AB0495

POST-MARKETING SURVEILLANCE OF TOFACITINIB IN JAPANESE PATIENTS WITH RHEUMATOID ARTHRITIS: AN INTERIM REPORT OF SAFETY DATA

N. Tamura ${ }^{1}$, M. Kuwana ${ }^{2}$, T. Atsumi ${ }^{3}$, S. Takei ${ }^{4}$, M. Harigai ${ }^{5}$, T. Fujii ${ }^{6}$, H. Matsuno ${ }^{7}$ T. Mimori ${ }^{8}$, S. Momohara ${ }^{9}$, K. Yamamoto ${ }^{10}$, K. Nomura $^{11}$, Y. Endo ${ }^{11}$ N. Sugiyama ${ }^{11}$, T. Hirose ${ }^{11}$, Y. Morishima ${ }^{11}$, N. Yoshii ${ }^{11}$, M. Takagi ${ }^{12}$. ${ }^{1}$ Juntendo University, Tokyo; ${ }^{2}$ Nippon Medical School, Tokyo; ${ }^{3}$ Hokkaido University, Sapporo; ${ }^{4}$ Kagoshima University, Kagoshima; ${ }^{5}$ Tokyo Women's Medical University, Tokyo; ${ }^{6}$ Wakayama Medical University, Wakayama; ${ }^{7}$ Matsuno Clinic for Rheumatic Diseases, Toyama; ${ }^{8}$ Kyoto University, Kyoto; ${ }^{9}$ Hakkeikai Inc Medical Institution, Shizuoka; ${ }^{10}$ The University of Tokyo, Tokyo; ${ }^{11}$ Pfizer Japan Inc, Tokyo;

${ }^{12}$ Yamagata University Faculty of Medicine, Yamagata, Japan

Background: Tofacitinib is an oral Janus kinase inhibitor for the treatment of rheumatoid arthritis (RA). Efficacy and safety of tofacitinib have been shown in patients (pts) with RA in global Phase (P)2, P3 and a long-term extension (LTE) study and in 2 P2 and 1 LTE study in Japanese pts.

Objectives: To evaluate safety of tofacitinib following drug approval in Japanese pts with RA using all-case post-marketing surveillance (PMS) data.

Methods: An interim analysis (IA) of safety data from an ongoing 3 year PMS study was conducted (5 Nov 2017 data-cut). All Japanese RA pts receiving tofacitinib were prospectively registered in the PMS study. All adverse events (AEs) were collected during tofacitinib treatment. Follow-up surveillance after discontinuation was conducted for serious infection events (SIEs; 1 year), malignancy and death ( 3 years). For all AEs and serious AEs, 6 month IA data was used. For AEs of special interest, all-period data (up to 36 months) was used to calculate cumulative incidence rates (IRs: pts with events/100 pt-years [yrs]) over time for herpes zoster $(\mathrm{HZ})$ and SIEs during treatment +28 days and for malignancies during the full observation period.

Results: Overall, 3929 tofacitinib-treated pts with 1704.1 pt-yrs of exposure were included in the 6 month IA of safety: $80.5 \%$ were female, mean age was 62.7 years, with $32.6 \%$ of pts $\geq 70$ years. Of these, 892 pts (22.7\%) discontinued treatment, mainly due to AEs (351 pts; $8.9 \%$ ) or lack of effectiveness (335 pts; 8.5\%). At least one $A E$ was observed in 1313 pts (33.4\%); infections were observed in 493 pts (12.5\%). The most frequent AEs were $\mathrm{HZ}$ (145 pts; $3.7 \%$ ) and abnormal hepatic function (72 pts; $1.8 \%)$. SAEs occurred in $287 \mathrm{pts}(7.3 \%)$; the most frequent SAEs were $\mathrm{HZ}$ ( $24 \mathrm{pts} ; 0.6 \%$ ) and pneumonia/bacterial pneumonia (33 pts; $0.8 \%$ ). SIEs occurred in 130 pts (3.3\%). Malignancy (all causality) was reported in 25 pts $(0.6 \%)$; lymphoma/lymphoproliferative disorder occurred in 5 pts $(0.1 \%)$ and breast cancer in 3 pts $(0.08 \%)$. There were 21 deaths $(0.5 \%)$ during the 6 month period. The most common causes of death (including pts with multiple causes listed) were infection ( 6 cases) and malignancy (5 cases). For AEs of special interest from all-period data the IR of $\mathrm{HZ}$ (serious and non-serious) was 6.81 (264 pts; 3876 pt-yrs), the IR of SIEs was 5.38 (212 pts; 3941 pt-yrs) and the IR of malignancy was 1.25 (61 pts; 4874 pt-yrs).

Conclusions: This IA of tofacitinib PMS in Japan did not reveal any new or unexpected safety signals vs the tofacitinib RA clinical trials. IRs for $\mathrm{HZ}$ and malignancy were similar to IRs in clinical trials of tofacitinib in Japanese RA pts and the SIE IR was within the range reported in PMS of biologic treatments. Continuous monitoring of SAEs is required until the final PMS results.

Acknowledgements: Study sponsored by Pfizer Inc. Medical writing support was provided by A MacLachlan of CMC and funded by Pfizer Inc.

Disclosure of Interest: N. Tamura Grant/research support from: AbbVie, Astellas, Bristol-Myers Squibb, Chugai, Eisai, Janssen, Mitsubishi-Tanabe, Takeda, Speakers bureau: AbbVie, Astellas, Bristol-Myers Squibb, Eisai, Janssen, Mitsubishi-Tanabe, M. Kuwana Grant/research support from: Ayumi, Chugai, Eisai, Mitsubishi-Tanabe, Ono, Pfizer Inc, Speakers bureau: Astellas, Chugai, Eisai, Janssen, Mitsubishi-Tanabe, Ono, Pfizer Inc, UCB, T. Atsumi Grant/research support from: Alexion, Astellas, Bristol-Myers Squibb, Chugai, Eisai, Janssen, Mitsubishi-Tanabe, Sanofi Scholarship donations from: Bayer, Daiichi-Sankyo, Takeda, Speakers bureau: AbbVie, Astellas, Chugai, Eisai, Mitsubishi-Tanabe, Takeda, Pfizer Inc, UCB Japan, S. Takei Grant/research support from: Chugai, Eisai, Mitsubishi-Tanabe, Takeda, Speakers bureau: Asahi-kasei, Ayumi, Chugai, Mitsubishi-Tanabe, Ono, M. Harigai Grant/research support from: Eisai, Takeda, Teijin, Consultant for: AbbVie, Ayumi, Bristol-Myers Squibb, Chugai, Janssen, Pfizer Inc, Paid instructor for: Takeda, T. Fujii Shareholder of: AbbVie, Ayumi, Bristol-Myers Squibb, Chugai, Janssen, Eisai, Mitsubishi-Tanabe, Ono, Grant/ research support from: Eisai, Mitsubishi-Tanabe, Ono, Daiichi-Sankyo, Pfizer Japan Inc, Speakers bureau: AbbVie, Mitsubishi-Tanabe, Ono, Pfizer Japan Inc., H. Matsuno Consultant for: Ayumi, Meiji Seika, Mochida, Nichi-Iko, T. Mimori Grant/research support from: Astellas, Ayumi, Chugai, Daiichi-Sankyo, Eisai, MSD, Mitsubishi-Tanabe, Sanofi, Taisho Toyama, Speakers bureau: Astellas, Bristol-Myers Squibb, Chugai, Eisai, Mitsubishi-Tanabe, S. Momohara Speakers bureau: AbbVie, Bristol-Myers Squibb, Eisai, Janssen, Pfizer Japan Inc, Ono, Takeda, Mitsubishi-Tanabe, K. Yamamoto Grant/research support from: AbbVie, Astellas, Ayumi, Chugai, Eisai, Mitsubishi-Tanabe, Nippon Kayaku, Pfizer Inc,

Takeda, Taisho Toyama, UCB, Teijin, Speakers bureau: Asahi-kasei, AstraZeneca, Ayumi, Boehringer Ingelheim, Bristol-Myers Squibb, Chugai, Eisai, Janssen, UCB, Mitsubishi-Tanabe, Pfizer Inc, Sanofi, Sumitomo Dainippon, TaishoToyama, Takeda, Teijin, K. Nomura Employee of: Pfizer Japan Inc, Y. Endo Employee of: Pfizer Japan Inc, N. Sugiyama Employee of: Pfizer Japan Inc, T. Hirose Employee of: Pfizer Japan Inc, Y. Morishima Employee of: Pfizer Japan Inc, N. Yoshii Employee of: Pfizer Japan Inc, M. Takagi Grant/research support from: Kaken, Taisho-Toyama, Eizai, Hisamitsu, Chugai, Pfizer Inc, Kyocera, Nihon Zoki, MSD, Astellas, AbbVie, Daiichi-Sankyo, Teijin, Takeda, Mitsubishi-Tanabe, Shionogi

DOI: 10.1136/annrheumdis-2018-eular.3521

\title{
AB0496 \\ T2T WITH SUBCUTANEOUS METHOTREXATE IN VERY EARLY RHEUMATOID ARTHRITIS (RA)
}

N. Chichasova ${ }^{1,2}$, G. Imametdiniva ${ }^{1}$, E. Nasonov ${ }^{1,2},{ }^{1}$ Nasonova State Institute of Rheumatology, ${ }^{2}$ Federal State Autonomous Educational of Institution of Higher Education I.M. Sechenov First Moscow State Medical University of the Ministry of Health of the Russian Federation, Moscow, Russian Federation

Objectives: Adherence to foundations T2T and education of patients (pts) according to T2T Connect program increase possibility of favourable outcome of RA

Methods: In open prospective 36 months study of efficacy and safety of subcutaneous methotrexate (MT) 74 pts with definite very early RA (ACR/EULAR 2010 were included: mean age was $45,2 \pm 15,9$, mean duration of RA $-5.2 \pm 3.48$ months, mean DAS28 - 5.66 \pm 1.99 ( $\max 7.06$, min 4.44$)$, RF positivity $73 \%$ and ACCP positivity $77 \%$ of pts. 3 pts had joint erosions. FK II had $43 \%$ and III- $53 \%$ of pts. Education conducted by program T2T Connect. Initial dose of MT was $15 \mathrm{mg} /$ week, all pts used 5-10 mg/week folic acid and NSAIDs in therapeutically dose according to comorbidities, systemic glucocorticoids (GK) were not prescribed. 72 pts completed 12 months of treatment, 54-24 months, 29-36 months.

Results: In $88 \%$ of pts improvement was observed in first 4-5 weeks. After 3 months low disease activity (LDA) was registered in 18 pts, in over pts therapy wasn't corrected in view with clear tendency to decrease of RA activity, intraarticular injection of GK was performed in 3pts. Changes of DAS28 are in the table 1 After 6 months moderate disease activity was in $49 \%$ of pts, LDA - in $51 \%$. After 12 months of study in all pts target of treatment was achieved: LDA in $81 \%$ of pts and remission (ACR/EULAR 2010 in 19\%; after 24 months 57\% and 43\% respectively, after 36 months $-36 \%$ and $64 \%$ respectively (18 pts without treatment). The minimal radiographic progression was observed in 18 pts $(24 \%$, mean erosion's score 1.63 \pm 1.02 ), that wasn't cause of firm decrease of functional ability in pts. 3 women with remission after 18 and 20 months of treatment with MT became pregnant and gave birth to normal newborns. Withdraw MT because of AE was in 2 pts (flu-syndrome).

In $88 \%$ of pts improvement was observed in first $4-5$ weeks. After 3 months low disease activity (LDA) was registered in 18 pts, in over pts therapy wasn't corrected in view with clear tendency to decrease of RA activity, intraarticular injection of GK was performed in 3pts. Changes of DAS28 are in the table 1. After 6 months moderate disease activity was in $49 \%$ of pts, LDA - in $51 \%$. After 12 months of study in all pts target of treatment was achieved: LDA in $81 \%$ of pts and remission (ACR/EULAR 2010 in 19\%; after 24 months 57\% and 43\% respectively, after 36 months $-36 \%$ and $64 \%$ respectively (18 pts without treatment). The minimal radiographic progression was observed in $18 \mathrm{pts}(24 \%$, mean erosion's score $1.63 \pm 1.02$ ), that wasn't cause of firm decrease of functional ability in pts. 3 women with remission after 18 and 20 months of treatment with MT became pregnant and gave birth to normal newborns. Withdraw MT because of AE was in 2 pts (flusyndrome).

Abstract AB0496 - Table 1

\begin{tabular}{lcccccc}
\hline Months & 0 & 3 & 6 & 12 & 24 & 36 \\
\hline Mean DAS28 $\pm S D$ & $5.66 \pm 1.77$ & $4.41 \pm 2.09$ & $3.25 \pm 1.63$ & $2.72 \pm 1.10$ & $2.81 \pm 1.75$ & $2.69 \pm 1.14$ \\
\hline
\end{tabular}

Conclusions: Peculiarity of our group of pts was the beginning of the treatment by MT, in most cases, at the first 6 months of RA onset. It is possible in this case to achieve remission more, than in half of pts without GK treatment. Thus, the subcutaneous form of MT is effective as regards activity and progression in early RA, safety for the long time in case of the using principles of controlled treatment allows achieve target after 6-12 month of therapy in most of pts with RA

Disclosure of Interest: None declared

DOI: 10.1136/annrheumdis-2018-eular.3687 